\title{
Immunological abnormalities in islets at diagnosis paralleled further deterioration of glycaemic control in patients with recent-onset Type I (insulin-dependent) diabetes mellitus
}

\author{
A. Imagawa ${ }^{1}$, T. Hanafusa ${ }^{1}$, N. Itoh ${ }^{2}$, M. Waguri ${ }^{1}$, K. Yamamoto ${ }^{1}$, J. Miyagawa ${ }^{1}$, M. Moriwaki ${ }^{1}$, K. Yamagata ${ }^{1}$, \\ H. Iwahashi ${ }^{1}$, M. Sada ${ }^{3}$, T. Tsuji ${ }^{3}$, S. Tamura ${ }^{1}$, S. Kawata ${ }^{1}$, M. Kuwajima ${ }^{4}$, H. Nakajima ${ }^{1}$, M. Namba ${ }^{1}$, Y. Matsuzawa ${ }^{1}$ \\ ${ }^{1}$ Department of Internal Medicine and Molecular Science, Graduate School of Medicine, Osaka University, Japan \\ ${ }^{2}$ Diabetes Centre, Toyonaka Municipal Hospital, Japan \\ ${ }^{3}$ Department of Surgical Research, Research Institute, National Cardiovascular Centre, Japan \\ ${ }^{4}$ Department of Laboratory Medicine, School of Medicine, Tokushima University, Japan
}

\begin{abstract}
Aims/hypothesis. To determine whether the clinical heterogeneity observed in the development of Type I (insulin-dependent) diabetes mellitus correlates with immunohistochemical differences observed at diagnosis.

Methods. Patients $(n=17)$ with recent-onset diabetes clinically considered to be insulin dependent (Type I), underwent pancreatic biopsy for immunohistological analysis. These patients were divided into two groups based on the presence or absence of islet immunological abnormalities (insulitis or hyperexpression of MHC class I antigens or both). The patients were also HLA typed and tested for islet cell antibodies and antibodies to glutamic acid decarboxylase (GAD-Ab). All patients were followed monthly for 2 years and their fasting plasma glucose, haemoglobin $\mathrm{A}_{1 \mathrm{C}}$ and daily insulin doses were recorded. The clinical course of patients with islet immunological abnormalities was compared with that of patients without those abnormalities.
\end{abstract}

Results. Patients with and without islet immunological abnormalities did not differ with regard to HLA type or islet cell antibodies. Antibodies to glutamic acid decarboxylase correlated with the presence of insulitis and MHC class I hyperexpression. These local immunological abnormalities were also associated with higher haemoglobin $\mathrm{A}_{1 \mathrm{C}}$ values $(p<0.05)$ and a trend towards greater insulin requirements. Further, patients with the islet abnormalities had higher fasting plasma glucose concentrations 2 years after the biopsy than at the time of the biopsy $(p<0.05)$. Conclusion/interpretation. The heterogeneous clinical course observed following diagnosis in patients with Type I diabetes correlates with islet immunological abnormalities. Insulitis and hyperexpression of MHC class I correlate with deteriorating glycaemic control. [Diabetologia (1999) 42: 574-578]

Keywords Type I diabetes, insulitis, ICA, GAD, biopsy, immunohistochemistry, HLA typing.
Type I (insulin-dependent) diabetes mellitus results from the selective destruction of pancreatic beta cells

Received: 28 September 1998 and in final revised form: 30 November 1998

Corresponding author: A. Imagawa, Department of Internal Medicine and Molecular Science, Graduate School of Medicine, B5, Osaka University, 2-2 Yamadaoka, Suita 565-0871, Japan

Abbreviations: AP, Autoimmune-proven; AUP, autoimmuneunproven; ICA, islet cell antibodies; GAD-Ab, antibodies to glutamic acid decarboxylase; JDFU, Juvenile Diabetes Foundation Units. and is considered to be a cell-mediated autoimmune disease [1]. To understand the pathogenesis of the disease better we studied pancreatic biopsy specimens from recent-onset Type I diabetic patients. These studies showed hyperexpression of MHC class I antigens and that the predominant islet-infiltrating cells to be $\mathrm{CD}^{+} \mathrm{T}$ cells and macrophages [2-3]. Others have examined autopsy specimens from Type I diabetic patients and have reported similar immunohistological findings [4-6].

We previously reported the surprising observation that only about half of the biopsies from patients with recent-onset Type I diabetes display the charac- 
Table 1. Patient's profiles and clinical and experimental data

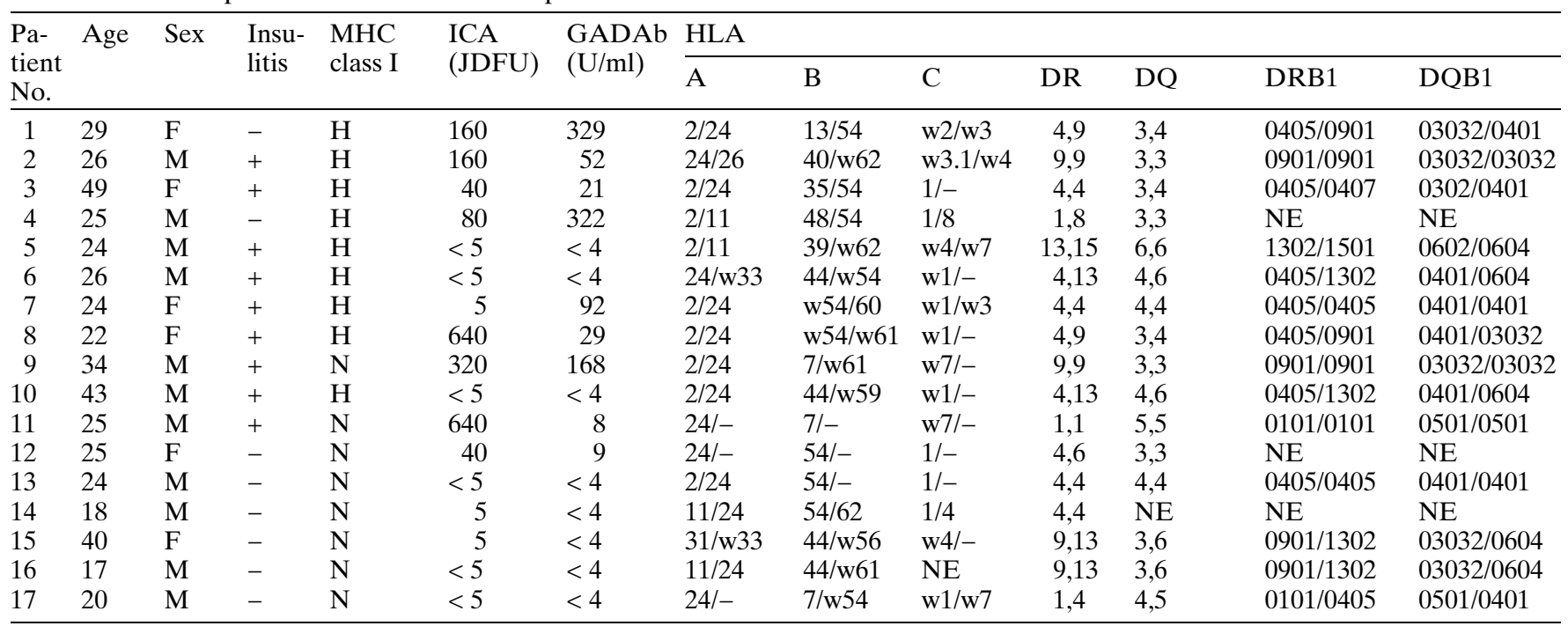

$\mathrm{H}$, hyperexpression in islets; $\mathrm{N}$, normal expression in islets; NE, not examined

teristic immunohistological findings of insulitis or MHC class I hyperexpression or both [2-3]. The patients whose biopsies did not show either insulitis or MHC class I hyperexpression otherwise manifested all the typical Type I diabetic clinical characteristics. Similar patients have been reported among Caucasians $[5,7]$. They were diagnosed using clinical criteria as having typical Type I diabetes but minimal or no insulitis was observed in their pancreas specimens at autopsy. These findings suggest that Type I diabetes is an immunohistologically heterogeneous disease with perhaps a more multi-factorial pathophysiology than is currently appreciated.

Recently, the expert committee on the diagnosis and classification of diabetes mellitus proposed that Type I diabetes resulted from mainly "immune-mediated" beta-cell destruction, except for a few "idiopathic" cases [8]. Nevertheless, detailed immunohistological features have not been correlated with temporal changes in clinical status. We therefore studied the immunohistological features present in pancreatic biopsy specimens from patients with recent-onset Type I diabetes and followed the clinical status of these patients for 2 or more years after the onset of the disease.

\section{Subjects and methods}

Patients. Patients $(n=17)$ with recent-onset diabetes clinically consistent with the early Type I disease were recruited for this study. Accordingly, all patients were lean and presented with some degree of ketosis. They were therefore started immediately on insulin therapy. Only patients with an initial C-peptide excretion of $5 \mu \mathrm{g} /$ day were included in the study because we wished to study the effect of immunohistological abnormalities on the beta-cell function still present when diabetes first became clinically manifest. Written informed consent was ob- tained from all the study patients before the pancreatic biopsy was carried out as previously reported [2-3]. The 17 patients were then divided into two groups based on the immunohistological analysis of their biopsy specimen. Those patients ( $n=11,1-11$ on Table 1$)$ who displayed insulitis or the hyperexpression of MHC class I antigens or both were designated the autoimmune-proven (AP) group. The biopsies from six patients (12-17 on Table 1) displayed no immunological abnormalities and this group was designated the autoimmune-unproven (AUP) group. The time from diagnosis to biopsy was similar for the two groups; 3.3 months (range 1-7 months) for the AP and 3.5 months (range 0-7 months) for the AUP group.

HLA typing and clinical characteristics at diagnosis. At the time of the diagnosis we documented: age, sex, body mass index (BMI), $\mathrm{HbA}_{1 \mathrm{C}}$, urinary C-peptide secretion, presence or absence of a family history of diabetes and presence or absence of probable infection preceding diabetes onset. In addition, we determined HLA class I and class II subtypes.

Islet autoantibodies. At the time of the biopsy, we also assayed each patient's serum for islet cell antibodies (ICA) and GAD$\mathrm{Ab}$ using an indirect immunofluorescent method and a radioimmunoassay, respectively [9]. Values greater than 5 Juvenile Diabetes Foundation Units (JDFU) were considered positive for the ICA and greater than $5 \mathrm{U} / \mathrm{ml}$ were considered positive for the GAD-Ab. The fourth and fifth ICA proficiency tests done under the auspices of the Immunology and Diabetes Workshops determined that our laboratory had a $100 \%$ sensitivity and specificity.

Long-term clinical features. All patients were admitted to hospital for their pancreatic biopsy and were subsequently followed in our diabetes outpatient clinic. All patients were treated with multiple daily insulin injections and self-monitored their blood glucose aiming to maintain normoglycaemia. Each patient's daily insulin doses were monitored and documented once a month. Each patient visited the laboratory once a month for a fasting plasma sugar and $\mathrm{HbA}_{1 \mathrm{C}}$ determination.

Statistical analysis. Statistical analysis was by Chi-squared test, Mann-Whitney U test or Student's $t$-test where appropriate. 

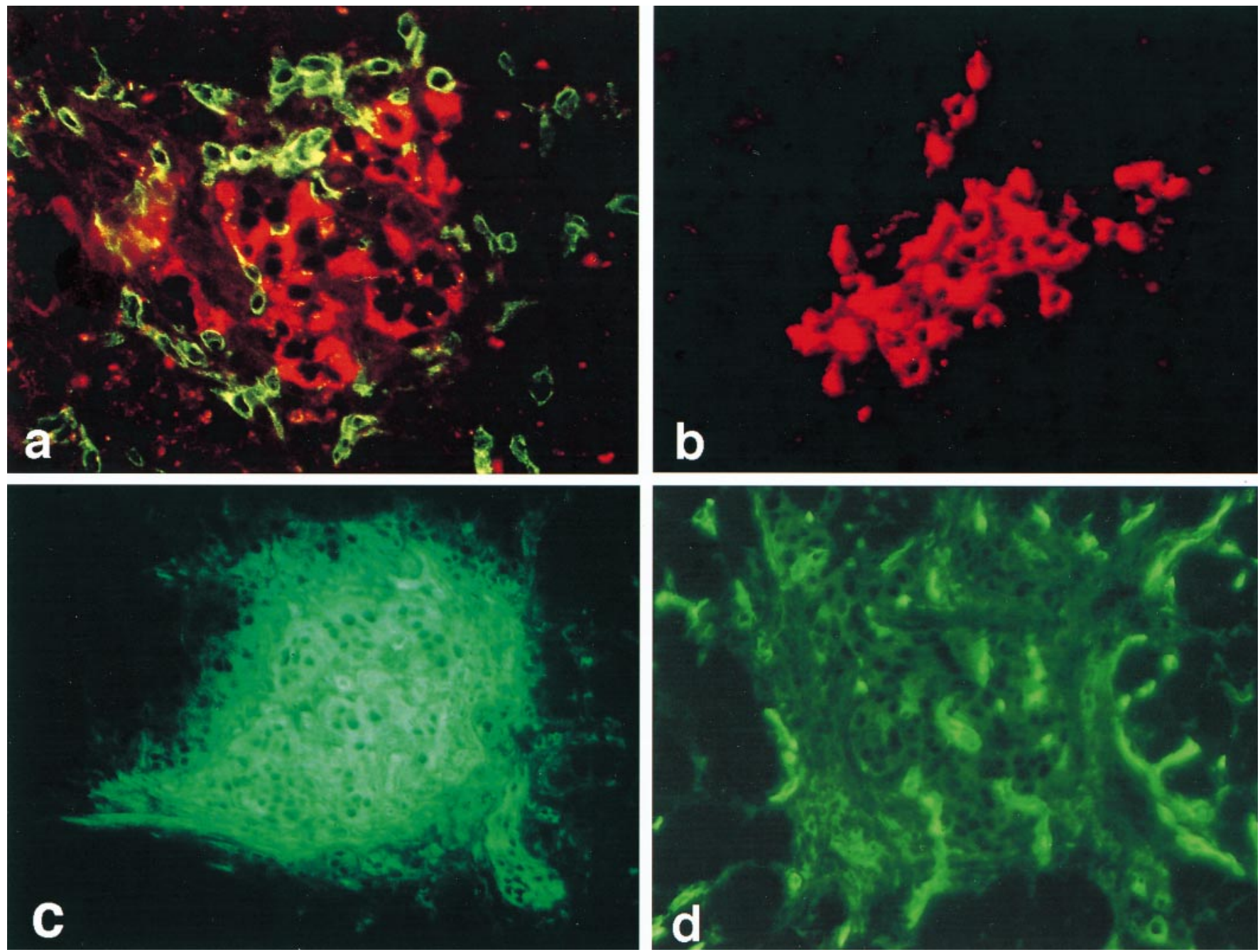

Fig. 1.a-d Photomicrographs of biopsies showing a insulitis (patient 10) compared with $\mathbf{b}$ an un-infiltrated islet (patient 16) and c an islet with increased MHC class I expression (patient 10) compared with d one with the more typical faint expression (patient 16). Glucagon-positive islet cells are shown in red and $\mathrm{CD}^{+} \mathrm{T}$ cells are shown in green

\section{Results}

Immunological and immunohistological analysis. All immunological and immunohistological data for the 17 patients is shown in Table 1 . In the six AUP patients, six $D Q B 1$ alleles are considered to be diabetes susceptible and two to be neutral. In the $11 \mathrm{AP}$ patients, $14 D Q B 1$ alleles are considered to be diabetes susceptible, 5 neutral and 1 resistant for Type I diabetes [10]. Although the sample is small, we observed no significant difference between the AP and AUP patients in HLA class I and class II antigens and the genotype of HLA-DRB1 or DQB1 antigens. Typical photomicrographs showing the appearance of an inflamed islet (insulitis) compared with an un-infiltrat-

ed islet together with an islet with increased MHC class I expression as opposed to one with the more typical faint expression are represented in Fig.1. All 17 patients were found to harbour residual beta cells. We examined, on average ( \pm SD), $104( \pm 98)$ islets in AP patients and $60( \pm 45)$ islets in the AUP patients. In those biopsy specimens showing insulitis and using an islet counting method we have reported previously [3], we found $20.9 \pm 22.6 \%$ of the islets to be affected islets (means \pm SD). Immunological abnormalities in islets were correlated with the existence of GAD-Ab $(p<0.05$, chi-squared analysis).

Clinical characteristics at diabetes onset. At the time of diabetes diagnosis, there were no significant differences between AP and AUP patients in (all data expressed as mean $\pm \mathrm{SD})$ : age $(29.7 \pm 8.7,24.0 \pm 8.5)$, sex $\quad($ men/women $=7 / 4, \quad 4 / 2), \quad$ BMI $\quad(18.8 \pm 1.9$, $17.2 \pm 2.0), \mathrm{HbA}_{1 \mathrm{C}}$ values $(11.0 \pm 2.4,11.4 \pm 1.4)$ and urinary C-peptide secretion $(22.7 \mu \mathrm{g} /$ day \pm 11.6 , $32.3 \mu \mathrm{g} /$ day \pm 7.9 ). None of the patients had a relative with Type I diabetes but 6 of the 11 patients in the AP group and 5 of the 6 patients in AUP group had relatives with Type II (non-insulin-dependent) diabetes 

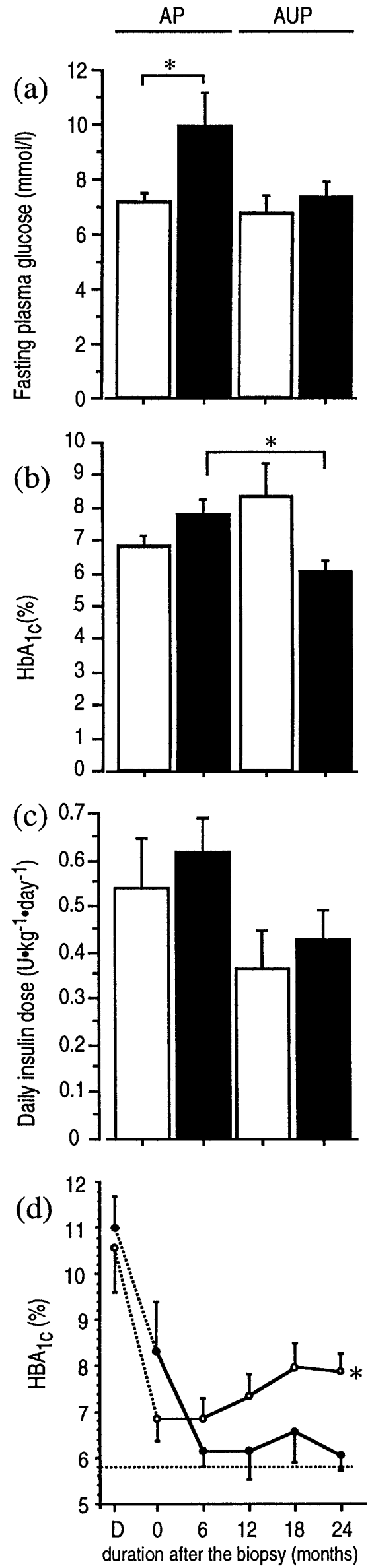

mellitus. Signs or symptoms suggesting antecedent infection were observed in 4 of the 11 AP patients and 4 of the 6 AUP patients. Lastly, at diagnosis there was no significant difference between AP and AUP patients in fasting plasma glucose, $\mathrm{HbA}_{1 \mathrm{C}}$ or daily insulin dose (Fig. 2).

Clinical characteristics on follow-up. Although fasting plasma glucose concentrations in AUP patients did not change over the 2-year observation period after pancreatic biopsy, these concentrations increased in the AP patients $(p<0.05)$ (Fig. 2). The $\mathrm{HbA}_{1 \mathrm{C}}$ values were also higher in the AP than in the AUP group at the end of this period ( $p<0.05$, Fig. 2$)$, another indication of a gradual deterioration in control in the AP patients. Finally, we observed better glycaemic control in the AUP group despite their daily insulin requirements being lower than those of AP patients.

\section{Discussion}

We report that immunohistological analysis of pancreatic biopsy specimens correlates with the heterogeneous clinical course of Type I diabetes after initial diagnosis. Insulitis or MHC class I hyperexpression or both was observed in 11 of the 17 patients and their glycaemic control deteriorated during the post-diagnosis 2-year follow-up period. On the other hand, 6 of 17 patients did not show the immunohistological changes at diagnosis and their glycaemic control was better despite relatively smaller daily insulin doses during the 2-year post-diagnosis follow-up. The improved glycaemic control with small insulin doses observed in the AUP group almost certainly reflects residual beta-cell function [11-12]. After the onset of Type I diabetes, the patients in which islet immunological abnormalities had been observed probably gradually lost their remaining beta-cells (insulin-secreting capacity) resulting in the deteriorating glycaemic control which we observed. Our results are supported by a previous report which found similar heterogeneity in the clinical course of patients with Type I diabetes depending on their ICA titre [13].

Fig. 2.a-d Chronic glycaemic control is predicted by the presence or absence of in situ immunohistological abnormalities. Fasting plasma glucose concentrations (a), $\operatorname{HbA}_{1 \mathrm{C}}(\mathbf{b})$ and daily insulin dose (c) are shown as means \pm SEM $(* p<0.05)$. Open bars indicate data at the time of biopsy and closed bars 2 years after the biopsy. (d) shows the $\mathrm{HbA}_{1 \mathrm{C}}$ measured every 6 months after the pancreatic biopsy (means \pm SEM). $\bigcirc$, mean $\mathrm{HbA}_{1 \mathrm{C}}$ from the AP group and $\mathrm{O}$, the values from the AUP group. ---, the $\mathrm{HbA}_{1 \mathrm{C}}$ upper limit of normal. (* $p<0.05$ vs AUP 2 years after the biopsy). D, at the time of initial diagnosis of diabetes. The 3 AP and 2 AUP patients are not included in (d) at the time of initial diagnosis of diabetes 
All the patients were clinically diagnosed with classical Type I diabetes based on the presenting features, e.g. all patients were lean and prone to ketosis. The Type I diagnosis was then supported by the histological finding of beta-cell depletion, an observation we have reported previously [14]. Notably, the betacells of the patients without in situ immunohistological abnormalities were decreased to the same extent as those of the patients with such abnormalities. In addition, we found no significant differences between the two groups in: age, sex, BMI, $\mathrm{HbA}_{1 \mathrm{C}}$, urinary C-peptide secretion, signs of antecedent infection, HLA type or disease duration before insulin therapy. Similarly, in data not shown, we found no difference between the AP and AUP groups either in: peripheral lymphocyte subsets $\left(\mathrm{CD}^{+}\right.$cells, $\mathrm{CD} 4^{+}$cells, $\mathrm{CD} 8^{+}$ cells, natural killer cells, interleukin-2 receptor positive cells and HLA-DR ${ }^{+}$cells) or the titre of viral antibodies to mumps, measles, rubella, cytomegalovirus, Epstein-Barr, and coxackie B4 virus. Despite these similarities, the clinical course after disease onset was different between the two groups.

The presence of at least two clinically distinct groups with recent-onset Type I diabetes suggests the existence of at least two different mechanisms leading to beta-cell death. In AP patients, beta-cells appear to be damaged via a cell-mediated autoimmune pathway before and even after the onset of overt diabetes. Our data suggest that $\mathrm{CD} 8^{+}$-cytotoxic $\mathrm{T}$ cells have an important pathogenic role. This is based on two observations. Firstly, the $\mathrm{CD}^{+}$cells predominate in the infiltrate and secondly we have consistently observed the hyperexpression of MHC class I in the islet cells [2-3]. Our data does not allow us to comment on the pathogenesis of beta-cell destruction in the AUP patients, but we found no evidence for an autoimmune mechanism. We surmise that a genetic disorder or direct viral attack on the pancreas contributed to the decreased beta-cell mass we observed. Others, for example, have reported patients with a clinical diagnosis of Type I diabetes to have an associated mitochondrial DNA mutation and severe loss of beta-cell volume [15]. Another group reported a Type I diabetic patient who was ICA-negative, this apparently having been caused by a cytomegalovirus infection [16].

We conclude from this study that the heterogeneous clinical course following the onset of Type I diabetes is associated with islet immunological abnormalities seen at diagnosis. The presence of either insulitis or MHC class I hyperexpression is associated with clear clinical evidence of ongoing beta-cell loss.

Acknowledgements. We would like to thank Dr. S. Tarui for his kind help in facilitating this research. We also wish to thank Dr. D.M. Harlan for his excellent comment. This work was supported by Grants-in-aid by The Ryoichi Naito Foundation for Medical Research, Ministry of Education, Culture and Sciences in Japan and the Ministry of Health and Welfare in Japan.

\section{References}

1. Bach JF (1994) Insulin-dependent diabetes mellitus as an autoimmune disease. Endocr Rev 15: 516-542

2. Hanafusa T, Miyazaki A, Miyagawa J et al. (1990) Examination of islets in the pancreas biopsy specimens from newly diagnosed type 1 (insulin-dependent) diabetes mellitus. Diabetologia 33: 105-111

3. Itoh N, Hanafusa T, Miyazaki A et al. (1993) Mononuclear cell infiltration and its relation to the expression of major histocompatibility complex antigens and adhesion molecules in pancreas biopsy specimens from newly diagnosed insulin-dependent diabetes mellitus patients. J Clin Invest 92: 2313-2322

4. Bottazzo GF, Dean BM, McNally GM, McKay EH, Swift PGF, Gamble DR (1985) In situ characterization of autoimmune phenomena and expression of HLA molecules in the pancreas in diabetic insulitis. N Engl J Med 313: 353-360

5. Foulis AK, Farquharson MA, Hardman R (1987) Aberrant expression of Class II major histocompatibility complex molecules by B cells and hyperexpression of Class I major histocompatibility complex molecules by insulin containing islets in type 1 (insulin-dependent) diabetes mellitus. Diabetologia 30: 333-343

6. Somoza N, Vargas F, Roura-Mir C et al. (1994) Pancreas in recent onset insulin-dependent diabetes mellitus. Changes in HLA, adhesion molecules and autoantigens, restricted $\mathrm{T}$ cell receptor $\mathrm{V}$ beta usage, and cytokine profile. J Immunol 153: 1360-1377

7. Lernmark Å, Klöppel G, Stenger D et al. (1995) Heterogeneity of islet pathology in two infants with recent onset diabetes mellitus. Virchows Archiv 425: 631-640

8. The expert committee on the diagnosis and classification of diabetes mellitus. (1997) Report of the expert committee on the diagnosis and classification of diabetes mellitus. Diabetes Care 20: 1183-1197

9. Imagawa A., Hanafusa T, Itoh N, et al. (1996) Islet infiltrating T-lymphocytes in insulin-dependent diabetic patients express CD80 (B7-1) and CD86 (B7-2). J Autoimmun 9: 391-396

10. Thorsby E, Rønningen KS (1993) Particular HLA-DQ molecules play a dominant role in determining susceptibility or resistance to type I (insulin-dependent) diabetes mellitus. Diabetologia 36: 371-377

11. Hendriksen C, Faber OK, Drejer J, Binder C (1977) Prevalence of residual beta-cell function in insulin-treated diabetics evaluated by the plasma C-peptide response to intravenous glucagon. Diabetologia 13: 615-619

12. Fukuda M, Tanaka A, Tahara Y et al. (1998) Correlation between minimal secretory capacity of pancreatic betacells and stability of diabetic control. Diabetes 37: 81-88

13. Peig M, Gomis R, Ercilla G et al. (1989) Correlation between residual beta-cell function and islet cell antibodies in newly diagnosed type 1 diabetes-follow-up study. Diabetes 38: 1396-1401

14. Itoh N, Hanafusa T, Miyagawa J et al. (1992) Transthyretin (prealbumin) in the pancreas and sera of newly-diagnosed type 1 (insulin-dependent) diabetic patients. J Clin Endocrinol Metab 74: 1372-1377

15. Kobayashi T, Nakanishi K, Nakase H et al. (1997) In situ characterization of islets in diabetes with a mitochondria DNA mutation at nucleotide position 3243. Diabetes 46: 1567-1571

16. Yasumoto N, Hara M, Kitamoto Y, Nakayama M, Sato T (1992) Cytomegalovirus infection associated with acute pancreatitis, rhabdomyolysis and renal failure. Internal Medicine (Tokyo) 31: 426-430 